\title{
Rapid and automated leaf net photosynthetic rate determination for numerous phosphor- converted white-LED lights of different spectral distributions
}

\section{Yuanhao Chen ( $\nabla$ yuanhao-chen@outlook.com )}

The University of Tokyo https://orcid.org/0000-0002-8133-3290

\section{Ryo Matsuda}

The university of Tokyo, Japan

\section{Kazuhiro Fujiwara}

The university of Tokyo, Japan

\section{Research}

Keywords: Cos lettuce, Green-leaf lettuce, LED-artificial sunlight source system, Plant factories with artificial light, Red-leaf lettuce, Spectral photon-flux-density distribution

Posted Date: October 7th, 2020

DOI: https://doi.org/10.21203/rs.3.rs-86157/v1

License: (c) (1) This work is licensed under a Creative Commons Attribution 4.0 International License.

Read Full License 


\section{Abstract}

\section{Background}

Phosphor-converted white LEDs (PCW-LEDs) of numerous types with different relative spectral photonflux-density distributions (SPDs) are commercially available today. Some are regarded as promising light sources for plant factories with artificial lighting. Therefore, some methods must be developed for rapidly selecting appropriate ones from numerous types of PCW-LEDs with relevant evaluation criteria. For rapid determination of leaf net photosynthetic rates $\left(P_{\mathrm{n}}\right)$ under dozens of PCW-LED lights with different SPDs, we have developed a rapid and mostly automated $P_{\mathrm{n}}$-quantification method.

\section{Results}

The method uses a modified LED-artificial sunlight source system (LASS system) and a $P_{\mathrm{n}}$-measurement system. The modified LASS system includes LEDs of 30 types with different relative SPDs: monochromatic LEDs of 27 types (426-826 nm peak wavelengths) and PCW-LEDs of three types. The system combines the LED lights to produce light with an SPD, which can accurately approximate that of any PCW-LED light at a photosynthetic photon flux density (PPFD) of $150 \mu \mathrm{mol} \mathrm{m} \mathrm{m}^{-2} \mathrm{~s}^{-1}$. The $P_{\mathrm{n}}$ quantification method includes two steps: Step 1 - producing the selected PCW-LED lights; Step 2 using the modified LASS system to supply all the produced lights automatically and successively to an identical leaf and simultaneously measuring $P_{\mathrm{n}}$ using a $P_{\mathrm{n}}$-measurement system. We produced PCW-LED lights of 30 types at a PPFD of $150 \mu \mathrm{mol} \mathrm{m} \mathrm{m}^{-2} \mathrm{~s}^{-1}$ within $2.5 \mathrm{~h}$. Then we individually measured the $P_{\mathrm{n}}$ of cos lettuce, red-leaf lettuce, and green-leaf lettuce (Lactuca sativa L.) plants under all produced lights in $16 \mathrm{~h}$ per cultivar per repetition. Results show that the mean $P_{\mathrm{n}}$ values of the cos lettuce, red-leaf lettuce, and green-leaf lettuce under the 30 produced lights were, respectively, 7.11-8.02, 5.76-7.11, and 4.83$6.17 \mu \mathrm{mol} \mathrm{m} \mathrm{m}^{-2} \mathrm{~s}^{-1}$ at 20 days after sowing.

\section{Conclusions}

A rapid and greatly automated method was developed for successive measurement of $P_{\mathrm{n}}$ under dozens of combined lights, of which each SPD approximated that of the selected PCW-LED lights, within days, which indicates that the method can determine the $P_{\mathrm{n}}$ quickly under numerous PCW-LED lights. Consequently, it contributes to the rapid selection of PCW-LED lights performing high $P_{\mathrm{n}}$.

\section{Background}

Because of their small size, long lifetime, and various relative spectral photon-flux-density distributions (SPDs), light-emitting diodes (LEDs) are particularly beneficial for cultivation in plant factories with artificial lighting (PFALs) [1-3]. The related literature shows that many researchers have investigated LED-SPD effects on the growth and development of various plant species [see a review, 1]. Most such studies have been conducted with blue LEDs (460-470 nm typical peak wavelength) and red LEDs 
(660 nm typical peak wavelength). This is because red light reportedly drives photosynthesis efficiently and adding small amounts of blue light to red light can increase photosynthesis and dry mass further [49]. However, under a combination of blue-LED and red-LED light (BR-light), plants appear to be purplishgray, which makes it difficult for growers to diagnose their health [3]. Adding green-LED light to BR-light (BGR-light) is one means of overcoming this difficulty because it produces white light when viewed by humans [10]. Several studies have revealed that the dry masses of some plants grown under BGR-light are equal to or greater than those under BR-light [10-13]. These reports have indicated indirectly that white light can be more effective than BR-light for plant dry mass production.

In recent years, PCW-LEDs have become an increasingly common white light source for investigating the effects of white-light SPD on plants [14-16]. A typical PCW-LED comprises a blue-LED chip and one or more types of phosphor incorporated in the encapsulation resin, of which the phosphors convert partial blue-LED light into green and/or red light [17]. Some reports have described that PCW-LED light can enhance plant growth compared to BR-light [16, 18, 19], even to BGR-light [11]. In addition, PCW-LEDs (blue-LED chip plus one or more types of phosphor) have been rapidly popularized for general lighting applications [16], of which the cost can be less than $20 \%$ of that of common red LEDs [20]. Because demand for PCW-LEDs is still increasing, their price can be expected to decrease further. Moreover, PCWLED light sources generally consist of one type of LED, which can be easier to manufacture than those with two or more types of LEDs, such as BGR-light sources. Considering these benefits of PCW-LEDs, they are expected to be promising plant cultivation light sources, especially for PFALs.

Currently, numerous types of PCW-LEDs with different relative SPDs are commercially available. In Japan, more than several dozen types of PCW-LED can be found. A PCW-LED SPD depends mainly on the phosphor types and their amounts contained in the encapsulation resin of the LED package. By adjusting these two factors, LED manufacturers can readily produce hundreds of thousands of PCW-LEDs with different relative SPDs.

A few studies have compared the performance of PCW-LEDs of several types in growing plants; they have shown that the relative SPD of PCW-LED light can strongly affect dry mass production $[11,18,19,21]$. These results indicate that selecting PCW-LEDs with an appropriate relative SPD is crucially important for PFAL proprietors when purchasing PCW-LEDs among commercially available ones. Therefore, the effects of the relative PCW-LED SPD on various plant responses should be investigated and quantified comprehensively.

Quantifying the $P_{\mathrm{n}}$ under PCW-LED lights with different relative SPDs is definitely a basic step of such studies. However, measuring $P_{\mathrm{n}}$ under more than dozens of PCW-LED lights with different relative SPDs might require more than a few months for preparation of all PCW-LED light sources. Moreover, measuring $P_{\mathrm{n}}$ with those PCW-LED light sources can be tedious because the operator taking measurements must repeat plant cultivations once for each light source to be tested. 
This study aimed at developing a rapid method for determining $P_{\mathrm{n}}$ under several dozen PCW-LED lights with different relative SPDs within days. For this purpose, we have developed a rapid and mostly automated $P_{\mathrm{n}}$-quantification method. The method uses two systems: a LASS system [22] and a photosynthesis measurement system. The LASS system contains 625 monochromatic LEDs with 32 peak wavelengths (385-910 nm). It was developed to produce light with an SPD approximating that of arbitrarily selected light at wavelengths of 385-910 nm within a few minutes. It can also supply an arbitrary number of the produced lights automatically and successively. Furthermore, their irradiation periods can be set individually at any interval of more than $2 \mathrm{~s}$. The LASS system can produce PCW-LED light with wavelengths mainly of $400-800 \mathrm{~nm}$. Stated briefly, the developed method determines $P_{\mathrm{n}}$ under selected PCW-LED lights by successively measuring $P_{\mathrm{n}}$ under each of the corresponding produced lights that is incident on an identical leaf.

For this study, we first modified the original LASS system to improve the approximation accuracy and maximum PPFD of the produced lights. The SPDs produced with the original system that approximate those of some PCW-LED lights show inadequate approximation accuracy for a PPFD of $150 \mu \mathrm{mol} \mathrm{m} \mathrm{m}^{-2} \mathrm{~s}^{-}$

${ }^{1}$ or greater. Subsequently, details of procedures used for the developed $P_{\mathrm{n}}$-quantification method are described. Lastly, using the method, we determined the $P_{\mathrm{n}}$ of three lettuce cultivars under 30 PCW-LED lights with different relative SPDs at a PPFD of $150 \mu \mathrm{mol} \mathrm{m}^{-2} \mathrm{~s}^{-1}$ within one day per cultivar per repetition. In addition, the performance of the lights produced with the modified LASS system (Fig. 1) and correlations between the determined $P_{\mathrm{n}}$ and the different wavelength-band light PFDs of the 30 PCW-LED lights were also discussed.

\section{Results}

Improved production of PCW-LED lights using the modified LASS system

The SPDs of the 30 produced lights obtained with the modified LASS system approximated, with adequate accuracy, those of the corresponding target PCW-LED lights (Fig. 2). In several produced lights, such as produced lights 27,28 , and 30 in Fig. 2, the differences between their SPDs and the corresponding target SPDs were slightly greater at wavelengths of $440-460 \mathrm{~nm}$ than those in other wavelength ranges. When the PPFDs of the target PCW-LED lights were set to $150 \mu \mathrm{mol} \mathrm{m}^{-2} \mathrm{~s}^{-1}$, the differences of the PPFDs among the 30 produced lights obtained with the original LASS system and those obtained with the modified one were within 5 and $2 \mu \mathrm{mol} \mathrm{m} \mathrm{m}^{-2} \mathrm{~s}^{-1}$, respectively (Additional file 1, Table S1). The root-mean-square errors (RMSEs) at every $1 \mathrm{~nm}$ between 400 and $800 \mathrm{~nm}$ of the 30 target and combined SPDs in the modified LASS system were all smaller than those in the original one at a PPFD of $150 \mu \mathrm{mol} \mathrm{m} \mathrm{m}^{-2} \mathrm{~s}^{-1}$ (Additional file 2, Table S2). The mean RMSE in the modified one was $0.08 \mu \mathrm{mol} \mathrm{m} \mathrm{m}^{-2} \mathrm{~s}^{-1} \mathrm{~nm}^{-1}$, which was approximately $50 \%$ of that in the original one. These results demonstrate quantitatively that the differences between the target and the produced SPDs in the modified LASS system at a PPFD of $150 \mu \mathrm{mol} \mathrm{m}^{-2} \mathrm{~s}^{-1}$ were markedly smaller than those in the original system at the same PPFD. 
When the PPFD of the target PCW-LED lights were set at $300 \mu \mathrm{mol} \mathrm{m}^{-2} \mathrm{~s}^{-1}$, the mean PPFD of the 30 produced lights in the modified LASS system was $301 \mu \mathrm{mol} \mathrm{m} \mathrm{m}^{-2} \mathrm{~s}^{-1}$, whereas that in the original one was $260 \mu \mathrm{mol} \mathrm{m} \mathrm{m}^{-2} \mathrm{~s}^{-1}$ (Additional file 1, Table S1). It is noteworthy that the maximum PPFD of produced light 1 obtained with the modified LASS system was $292 \mu \mathrm{mol} \mathrm{m} \mathrm{m}^{-2} \mathrm{~s}^{-1}$ (Additional file 1, Table S1). The mean RMSE at a PPFD of $300 \mu \mathrm{mol} \mathrm{m} \mathrm{m}^{-2} \mathrm{~s}^{-1}$ in the modified LASS system was $0.22 \mu \mathrm{mol} \mathrm{m} \mathrm{m}^{-2} \mathrm{~s}^{-1} \mathrm{~nm}^{-1}$, which was greater than that at a PPFD of $150 \mu \mathrm{mol} \mathrm{m} \mathrm{m}^{-2} \mathrm{~s}^{-1}$ in the modified LASS system (Additional file 2, Table S2).

$P_{\mathrm{n}}$ measurement

The mean $P_{\mathrm{n}}$ under the 30 produced lights at 20 days after sowing (DAS) and 25 DAS were 7.11-8.02 and 7.27-8.17 $\mu \mathrm{mol} \mathrm{m} \mathrm{m}^{-2} \mathrm{~s}^{-1}$ for the cos lettuce plants (Fig. 3), 5.76-7.11 and 5.89-7.18 $\mu \mathrm{mol} \mathrm{m}^{-2} \mathrm{~s}^{-1}$ for the red-leaf lettuce plants (Fig. 4), and 4.83-6.17 and 5.18-6.50 $\mu \mathrm{mol} \mathrm{m}^{-2} \mathrm{~s}^{-1}$ for the green-leaf lettuce plants (Fig. 5). For the three lettuce cultivars, the mean $P_{\mathrm{n}}$ under produced light 1 was significantly greater than that under the produced light 7-30 at 20 and 25 DAS. Moreover, the mean $P_{\mathrm{n}}$ under the produced light at 20 DAS and that at 25 DAS were comparable in the cos lettuce and green-leaf lettuce but not in the green-leaf lettuce, for which the value at 25 DAS tended to be greater than that at 20 DAS.

Correlations between $P_{\mathrm{n}}$ and different wavelength-band light SPDs

In the three lettuce cultivars, the mean $P_{\mathrm{n}}$, which was the mean values of the $P_{\mathrm{n}}$ under the produced lights at 20 DAS and that at 25 DAS, was significantly and negatively correlated to the blue-light $(400-500 \mathrm{~nm})$ and green-light (501-600 nm) PFDs of the PCW-LED lights, while significantly and positively correlated to the red-light (601-700 nm) and far-red-light (701-800 nm) PFDs (Fig. 6).

\section{Discussion}

To determine $P_{\mathrm{n}}$ rapidly under dozens of PCW-LED lights with different relative SPDs, we developed a rapid and greatly automated $P_{\mathrm{n}}$-quantification method. For this study, we demonstrated that the developed method can provide the $P_{\mathrm{n}}$ of 30 PCW-LED lights in one measurement automatically within one day.

Evaluating reliability of the determined $P_{\mathrm{n}}$ in terms of RMSEs of the target and combined SPDs

The reliability of the determined $P_{\mathrm{n}}$ using the proposed $P_{\mathrm{n}}$-quantification method depends primarily on the extent of spectral-photon-flux-density differences between the target and combined SPDs. The RMSE calculated from the spectral photon-flux-densities [ $\mu \mathrm{mol} \mathrm{m}^{-2} \mathrm{~s}^{-1} \mathrm{~nm}^{-1}$ ] of a target and the corresponding combined SPD at wavelengths of $400-800 \mathrm{~nm}$ was then used as an index to evaluate the average extent of the spectral-photon-flux-density differences between the two SPDs. Low RMSE, calculated from the two SPDs, was associated with small spectral photon-flux-density differences between them. The RMSEs 
of the 30 target and corresponding combined SPDs were less than $0.2 \mu \mathrm{mol} \mathrm{m}^{-2} \mathrm{~s}^{-1} \mathrm{~nm}^{-1}$ at a PPFD of $150 \mu \mathrm{mol} \mathrm{m} \mathrm{m}^{-2} \mathrm{~s}^{-1}$ (Additional file 2, Table S2). In fact, the differences of the PPFDs among the 30 combined SPDs were within $2 \mu \mathrm{mol} \mathrm{m} \mathrm{m}^{-2} \mathrm{~s}^{-1}$ (Additional file 1, Table S1) at the same PPFD level. In several produced lights (produced lights 27, 28, and 30 in Fig. 2), the differences between the target and combined SPDs were slightly greater at wavelengths of $440-460 \mathrm{~nm}$ than those in the other wavelength ranges, but these small differences might not lead to significant differences between the $P_{\mathrm{n}}$ under the target and the corresponding produced lights. Therefore, we inferred that the $P_{\mathrm{n}}$ measured under the 30 produced lights is sufficiently reliable to represent the $P_{\mathrm{n}}$ measured under the corresponding PCW-LED lights at a PPFD of $150 \mu \mathrm{mol} \mathrm{m} \mathrm{m}^{-2} \mathrm{~s}^{-1}$.

The mean PPFD of the 30 SPDs obtained with the modified LASS system has achieved $300 \mu \mathrm{mol} \mathrm{m} \mathrm{m}^{-2} \mathrm{~s}^{-}$ ${ }^{1}$, which is expected to be sufficient for a PFAL to grow leafy plants. It is noteworthy that the maximum PPFD of produced light 1 with the modified LASS system was $292 \mu \mathrm{mol} \mathrm{m}^{-2} \mathrm{~s}^{-1}$. In addition, the mean RMSE of the obtained SPDs at a PPFD of $300 \mu \mathrm{mol} \mathrm{m} \mathrm{m}^{-2} \mathrm{~s}^{-1}$ in the modified LASS system was $0.22 \mu \mathrm{mol}$ $\mathrm{m}^{-2} \mathrm{~s}^{-1} \mathrm{~nm}^{-1}$, which was approximately three times greater than that at aPFD of $150 \mu \mathrm{mol} \mathrm{m} \mathrm{m}^{-2} \mathrm{~s}^{-1}$. These results indicate that the present LASS system requires further modifications to obtain produced lights with low RMSEs at a PPFD of $300 \mu \mathrm{mol} \mathrm{m} \mathrm{m}^{-2} \mathrm{~s}^{-1}$, similarly to those at a PPFD of $150 \mu \mathrm{mol} \mathrm{m} \mathrm{m}^{-2} \mathrm{~s}^{-}$ 1 .

Saving time and labor before and during $P_{\mathrm{n}}$ measurements

The developed method determines $P_{\mathrm{n}}$ for the selected PCW-LED lights using the corresponding produced lights and by successively measuring $P_{\mathrm{n}}$ under more than 30 produced lights on an identical leaf. The modified LASS system can produce dozens of arbitrarily selected PCW-LED lights within hours, whereas the approach of successively measuring the $P_{\mathrm{n}}$ under dozens of lights directly from the PCW-LED light sources might take more than weeks or months to prepare all light sources. Another benefit of the LASS system is that it can reduce an experimenter's workload during $P_{\mathrm{n}}$ measurement with numerous PCW-LED lights. This labor-saving feature is achieved by virtue of the LASS system capability of automatically changing different lights during a $P_{\mathrm{n}}$ measurement. Without the LASS system, an experimenter would need to change different light sources and adjust their outputs manually to obtain the accurate PPFDs for every $30 \mathrm{~min}$ in a long period, such as $16 \mathrm{~h}$ in this study.

Limitations of the modified LASS system and possible solutions

For this study, the selected PCW-LEDs include a blue LED chip (approximately $460 \mathrm{~nm}$ peak wavelength) and one or more phosphors. Two other types of white LED [23] are commercially available. One is the near-ultraviolet LED type, which comprises a near-ultraviolet LED chip (approximately $410 \mathrm{~nm}$ peak wavelength) and some phosphors. This white-LED type has also been used to investigate the effects of SPD on $P_{\mathrm{n}}$ [24]. Another is the BGR type, which comprises blue, green, and red LED chips. The modified LASS system is applicable to light production, of which each SPD accurately approximates that of BGR- 
type-white-LED lights. However, it is not applicable to near-ultraviolet-type-white-LED lights because monochromatic LEDs with peak wavelengths shorter than $426 \mathrm{~nm}$ were removed from the present LED module. This limitation can be resolved simply by installing several types of near-ultraviolet-type monochromatic LEDs to the LED module.

Another limitation of the present LASS system is that it irradiates an area of only $7.1 \mathrm{~cm}^{2}$. This limited irradiated area can be sufficient for a small leaf chamber such as the LI-6400 or a small whole-plant chamber [25], but it is insufficient for a plant-organ chamber [26] or a whole-plant chamber [27]. This limitation, however, cannot be resolved easily because it requires a scaling up of the LED module by more than several times and a corresponding scaling up of the power supply for the LED module. Moreover, such a light source is expected to provide a uniform distribution on an irradiated area in terms of the PFD and relative SPD [28], which indicates that the arrangement of the LEDs installed on the LED module might need to be re-assessed.

Correlation between $P_{\mathrm{n}}$ and red-light or far-red-light SPD

In the three lettuce cultivars, the mean $P_{\mathrm{n}}$, which represents the mean value of the $P_{\mathrm{n}}$ under the produced lights at 20 DAS and that at 25 DAS, was highly positively correlated with red-light (601-700 nm) PFDs for PCW-LED light, although it was strongly negatively correlated with the green-light (501-600 nm) PFDs (Figs. 6B and 6C). These results indicate that the red light in the PCW-LED lights might be more efficient than the green light in driving photosynthesis of an identical lettuce leaf at a PPFD of $150 \mu \mathrm{mol} \mathrm{m} \mathrm{m}^{-2} \mathrm{~s}^{-1}$. Many studies have demonstrated that red light can bring about a greater $P_{\mathrm{n}}$ than green light in various plants at a low PPFD level [29-32]. In addition, a report described that the $P_{\mathrm{n}}$ under red light combined with white light is higher than that under green light combined with white light at a low PPFD level (less than $200 \mu \mathrm{mol} \mathrm{m} \mathrm{m}^{-2} \mathrm{~s}^{-1}$ ) [33].

Mean $P_{\mathrm{n}}$ was found to be highly positively correlated with far-red-light $(701-800 \mathrm{~nm})$ PFD in all lettuce cultivars (Fig. 6D). It is generally agreed that far-red light alone is much less efficient than green or red light for driving photosynthesis. Therefore, this result is expected to be attributable mainly to the fact that far-red light PFDs are positively correlated with red-light PFDs and negatively correlated with green-light PFDs (Additional file 3, Figure S1): a PCW-LED providing a high far-red light PFD tends to contain a high red-light PFD along with a low green-light PFD, which can potentially yield a high $P_{\mathrm{n}}$ (Figs. 6B and 6C).

\section{Conclusions}

To determine $P_{\mathrm{n}}$ under dozens of PCW-LED lights with different relative SPDs within days, we developed a rapid and automated $P_{\mathrm{n}}$-quantification method that uses a modified LASS system and a photosynthesis measurement system. The mean RMSEs of the 30 produced lights, of which each SPD obtained with the modified LASS system approximated that of the 30 selected PCW-LED lights, were $0.08 \mu \mathrm{mol} \mathrm{m} \mathrm{m}^{-2} \mathrm{~s}^{-1}$ $\mathrm{nm}^{-1}$ at a PPFD of $150 \mu \mathrm{mol} \mathrm{m} \mathrm{m}^{-2} \mathrm{~s}^{-1}$ and $0.22 \mu \mathrm{mol} \mathrm{m} \mathrm{m}^{-2} \mathrm{~s}^{-1} \mathrm{~nm}^{-1}$ at a PPFD of $300 \mu \mathrm{mol} \mathrm{m} \mathrm{m}^{-2} \mathrm{~s}^{-1}$, 
respectively. Using the developed method, we determined the individual $P_{\mathrm{n}}$ of three lettuce cultivars under 30 PCW-LED lights at a PPFD of $150 \mu \mathrm{mol} \mathrm{m} \mathrm{m}^{-2} \mathrm{~s}^{-1}$ within one day per cultivar per repetition. These results indicate that the developed method can contribute to the rapid selection of PCW-LEDs offering superior photosynthetic performance from numerous commercially available PCW-LEDs.

\section{Methods}

After briefly introducing the original LASS system, this report describes some modifications which were made of the LASS system. Finally, we describe procedure of a $P_{\mathrm{n}}$-quantification method developed for successive evaluation of $P_{\mathrm{n}}$ for 30 PCW-LED lights with different relative SPDs.

\section{Original LASS system}

The original LASS system [22] comprises a light source unit, an LED temperature control system, and a spectral irradiance distribution (SID) control system. The light source unit consists of an LED module and a hollow conical reflection condenser. The LED module is equipped with 625 monochromatic LEDs with 32 peak wavelengths $(385-910 \mathrm{~nm})$. The condenser is used to mix lights from different LEDs and to gather them to the light outlet. The LED temperature control system is assembled to stabilize the LED module temperature. The SID control system can produce light with an SID (combined SID) that accurately approximates a given SID (target SID) within a 380-940 nm wavelength. Because an SID can convert to an SPD at the same wavelength range, as described in a review of the literature [35], the SID control system is therefore an SPD control system. This function can be achieved because it can control SIDs on the light outlet by adjusting the voltages applied to each type of monochromatic LED. When a desirable SID is obtained, users can save the voltage set (voltages of the 32 types of LED) in the SID control system. The LASS system can then readily re-irradiate a light with any combined SID by loading its voltage set and applying the voltages to the LEDs. Furthermore, the SID control system can automatically supply more than dozens of produced lights successively. Moreover, the irradiation period of each light can be set at intervals of more than $2 \mathrm{~s}$.

Modified LASS system

Although the original LASS system can produce lights with different SPDs, accurately approximating those of the corresponding selected PCW-LED lights (a typical one is presented in Additional file 4, Figure S2A), the extent of the differences between some combined SPDs and the corresponding target SPDs in several wavelength ranges, such as $440-460 \mathrm{~nm}, 510-550 \mathrm{~nm}$, and $580-620 \mathrm{~nm}$ (a typical one is presented in Additional file 4, Figure S2B), was not negligible. These differences might engender biases between the $P_{\mathrm{n}}$ measured under the produced lights and that measured under the corresponding PCWLED lights. Another point to be improved was the low maximum-PPFDs of the produced lights with the original LASS system for PCW-LEDs, which were approximately $150 \mu \mathrm{mol} \mathrm{m}^{-2} \mathrm{~s}^{-1}$. Considering that the PPFD used in a PFAL can reach $300 \mu \mathrm{mol} \mathrm{m} \mathrm{m}^{-2} \mathrm{~s}^{-1}$ [38], the modified LASS system is expected to be capable of producing PCW-LED lights at a PPFD of over $300 \mu \mathrm{mol} \mathrm{m} \mathrm{m}^{-2} \mathrm{~s}^{-1}$. 
Therefore, we made the following modifications to the original LASS system to meet our requirements. First, we selected monochromatic LEDs of three types and PCW-LEDs of three types (Fig. 7; Additional file 5 , Table S3) to be installed on the modified LED module. Their peak wavelengths differed from those of the original LED module. The three PCW-LEDs to be installed were selected because their relative SPDs included some wavelength ranges that we can find only rarely in commercial monochromatic LEDs. In addition, their high photon fluxes per LED contribute to increased maximum PPFDs of the produced lights.

Then, we replaced monochromatic LEDs of eight types with selected LEDs of eight types with similar peak wavelengths to the original LED module; the eight types of LEDs have higher photon fluxes per LED. After those modifications, the modified LED module consists of monochromatic LEDs of 27 types (426$826 \mathrm{~nm}$ peak wavelengths) and PCW-LEDs of three types. Their relative SPDs, model codes, and peak wavelengths are shown in Fig. 7 and Additional file 5, Table S3.

Lastly, we coated the inner surface of the hollow conical reflection condenser with a water-based highreflectance barium sulfate coating (Avian-B500; Avian Technologies LLC, New London, NH, USA) to increase the distribution uniformity of the combined PFDs at the light outlet.

The RMSEs [mol m-2 $\mathrm{s}^{-1} \mathrm{~nm}^{-1}$ ] of the combined SPDs and the target SPDs were used to evaluate the extent of their mutual difference. For lower RMSE, better combined SPD is obtained.

Plant materials and growth conditions

Cos lettuce (cv. Cos Lettuce; Takii Seed Co. Ltd., Kyoto, Japan), red-leaf lettuce (cv. Mother-red; Takii Seed Co. Ltd.), and green-leaf lettuce (cv. Mother-green; Takii Seed Co. Ltd.) plants were subjected to $P_{\mathrm{n}}$ measurements at 20 and $25 \mathrm{DAS}$. They were cultivated in a growth chamber at $25 \pm 1{ }^{\circ} \mathrm{C}$ (mean $\pm \mathrm{SE}$ ) under a 16-h/8-h light/dark period cycle. A PCW-LED array (HMW120DC6 (1N-40Y); Kyoritsu Densho Co., Ltd., Osaka, Japan), shown as PCW-LED light 16 in Fig. 2, was applied to provide a PPFD of $150 \pm$ $10 \mu \mathrm{mol} \mathrm{m} \mathrm{m}^{-2} \mathrm{~s}^{-1}$ on the cultivation surface. The $\mathrm{CO}_{2}$ concentration in the growth chamber was $1000 \pm$ $50 \mu \mathrm{mol} \mathrm{mol}{ }^{-1}$ controlled by an infrared CO2 controller (ZFP9; Fuji Electric Co., Ltd., Tokyo, Japan). Lettuce plants were cultivated in a nutrient solution (half-strength Otsuka-A nutrient solution; OAT Agrio Co. Ltd., Tokyo, Japan) with an electrical conductivity of $150 \pm 0.1 \mathrm{mS} \mathrm{m}^{-1}$.

Procedure of the rapid and mostly automated $P_{\mathrm{n}}$-quantification method

\section{Step 1: Producing PCW-LED lights with the modified LASS system}

The general procedure to produce light with the modified LASS system (Fig. 8) is the following: 1) preparing the target-SID data, which include spectral irradiance at every $1 \mathrm{~nm}$ between 400 and $800 \mathrm{~nm}$; 
2) determining the voltage sets to gain the desired SID based on the target-SID data, and saving it to the LASS system.

The target-SID data of 30 types of PCW-LEDs (Fig. 2; Additional file 6, Table S4) were converted from their SPDs, as calculated from the relative SIDs of the selected PCW-LEDs at a PPFD of $150 \mu \mathrm{mol} \mathrm{m} \mathrm{m}^{-2} \mathrm{~s}^{-1}$. The relative SIDs are usually shown as figures in their specification sheets. A free web-based program [39] was used to obtain relative SIDs at every $1 \mathrm{~nm}$ between 400 and $800 \mathrm{~nm}$, from the figures shown in specification sheets.

The target-SID data were then imported to the SID control system to determine the appropriate voltage set to obtain the desired SIDs, and therefore the desired SPDs. The SPDs were measured using a spectroradiometer (MS720; Eko Instruments Co. Ltd., Tokyo, Japan) at the same surface of a leaf enclosed in the leaf chamber of the LI-6400 (Fig. 1). It is noteworthy that, in the $P_{\mathrm{n}}$ measurements, a steel plate was used as a connector to place the leaf chamber rigidly under the light outlet of the modified LASS system, just as it was placed in light production (Fig. 1). The steel plate was installed on the top of the leaf chamber and trepanned a hole, of which the shape and size were approximately the same as those of the light outlet.

\section{Step 2: Measurement of $P_{n}$ under the produced lights}

Before $P_{\mathrm{n}}$ measurement started, the irradiation order of the 30 produced lights was determined randomly (Fig. 9). The irradiation period of each produced light was set as $0.5 \mathrm{~h}$. During $P_{\mathrm{n}}$ measurement, the LASS system automatically supplied the produced light 16 (Fig. 2) for 1 h. Then the system supplied all 30 produced lights successively to an identical leaf according to the set order and period. Each $P_{\mathrm{n}}$ measurement was completed in $16 \mathrm{~h}$. An example of $P_{\mathrm{n}}$ measurement is presented in Fig. 10.

A plant was used for $P_{\mathrm{n}}$ measurement approximately six hours after the beginning of the light period at 20 or 25 DAS. The timing was set based on our preliminary experiment results, which showed that the $P_{\mathrm{n}}$ measured under one produced light kept increasing for approximately six hours after the beginning of the light period. An LI-6400 portable photosynthesis system (Li-Cor Inc. Lincoln, NE, USA) was used for $P_{\mathrm{n}}$ measurements. In the leaf chamber of the LI-6400 during the $P_{\mathrm{n}}$ measurements, the leaf temperature (mean $\pm \mathrm{SE}$ ), $\mathrm{CO}_{2}$ concentration, relative humidity, and airflow rate were, respectively, $25.0 \pm 0.1^{\circ} \mathrm{C}, 1000 \pm$ $1 \mu \mathrm{mol} \mathrm{mol}{ }^{-1}$, and $65 \pm 8 \%$ and $500.3 \pm 0.2 \mu \mathrm{mol} \mathrm{s}^{-1}$. During $P_{\mathrm{n}}$ measurement, the LI-6400 was set to record a dataset including $P_{\mathrm{n}}, \mathrm{CO}_{2}$ concentration, etc., automatically every $3 \mathrm{~s}$ and to match its two $\mathrm{CO}_{2}$ and $\mathrm{H}_{2} \mathrm{O}$ analyzers for reference and sample lines, respectively, after every ten datasets were recorded. On average, the LI-6400 recorded ten datasets (30 s) and matched its analyzers (approximately $30 \mathrm{~s}$ ) in approximately one minute. Therefore, approximately 300 datasets were compiled for each produced light. The last 100 datasets were used to calculate the mean $P_{\mathrm{n}}$ of that produced light. In all, five replications for each produced light with each lettuce cultivar were conducted at 20 and 25 DAS.

\section{Statistical analysis}


Significant differences in mean $P_{\mathrm{n}}$ among the 30 produced lights were tested using a $t$-test with HolmBonferroni correction for multiple comparisons, with significance inferred for $p<0.05$, using software ( $R$ 3.6.1, R Core Team, 2019). Correlation analyses between the mean $P_{n}$, which was the mean value of the $P_{\mathrm{n}}$ under the produced lights at 20 DAS and that at $25 \mathrm{DAS}$, and blue-light (400-500 nm) photon flux densities (PFDs), green-light PFDs (501-600 nm), red-light PFDs (601-700 nm), and far-red-light PFDs (701-800 nm) of the 30 PCW-LEDs were tested using Pearson correlation analysis, with significance inferred for $p<0.05$, using the same software.

\section{Abbreviations}

PCW-LED: phosphor-converted white LED; SPD:spectral photon-flux-density distribution; $P_{\mathrm{n}}$ :leaf net photosynthetic rate; LASS system:LED-artificial sunlight source system; PPFD:photosynthetic photon flux density; LED:light-emitting diode; PFAL:plant factory with artificial lighting; BR-light:combination of blueLED and red-LED light; BGR-light:combination of blue-LED, green-LED, and red-LED light; RMSE:root mean square error; DAS:days after sowing; SID:spectral irradiance distribution; PFD:photon flux density

\section{Declarations}

\section{Ethics approval and consent to participate}

Not applicable

\section{Consent for publication}

Not applicable

\section{Availability of data and materials}

All data generated or analyzed during this study are included in this published article and its supplementary information files.

\section{Competing interests}

The authors declare that they have no competing interests.

\section{Funding}

This work was financially supported in part by JSPS KAKENHI (grant number: 18H03966) to KF and RM. 


\section{Authors' contributions}

YH C developed the rapid leaf-photosynthesis-measurement method, modified the LED-artificial sunlight source system, conducted the leaf photosynthesis measurements, analyzed the data and drafted the manuscript. RM and KF participated in discussions of the results and modifications of the study design and then made critical revision of the manuscript. KF participated in the development of the rapid leafphotosynthesis measurement method. All authors read and approved the final manuscript.

\section{Acknowledgements}

Not applicable

\section{References}

1. Bantis F, Smirnakou S, Ouzounis T, Koukounaras A, Ntagkas N, Radoglou K. Current status and recent achievements in the field of horticulture with the use of light-emitting diodes (LEDs). Sci Hortic. 2018;235:437-51. doi.org/10.1016/j.scienta.2018.02.058.

2. Kozai T. Why LED lighting for urban agriculture? In: Kozai T, Fujiwara K, Runkle ES, editors. LED lighting for urban agriculture. Singapore: Springer; 2016. pp. 3-18. doi.org/10.1007/978-981-101848-0_1.

3. Massa GD, Kim H-H, Wheeler RM, Mitchell CA. Plant productivity in response to LED lighting. HortSci. 2008;43:1951-56. doi.org/10.21273/HORTSCI.43.7.1951.

4. Hernández R, Kubota C. Physiological responses of cucumber seedlings under different blue and red photon flux ratios using LEDs. Environ Exp Bot. 2016;121:66-74.

doi.org/10.1016/j.envexpbot.2015.04.001.

5. Kim S-J, Hahn E-J, Heo J-W, Paek K-Y. Effects of LEDs on net photosynthetic rate, growth and leaf stomata of chrysanthemum plantlets in vitro. Sci Hortic. 2004;101:143-51. doi.org/10.1016/j.scienta.2003.10.003.

6. Wang J, Lu W, Tong Y, Yang Q. Leaf morphology, photosynthetic performance, chlorophyll fluorescence, stomatal development of lettuce (Lactuca sativa L.) exposed to different ratios of red light to blue light. Front Plant Sci. 2016;7:250. doi.org/10.3389/fpls.2016.00250.

7. Lee S-H, Tewari RK, Hahn E-J, Paek K-Y. Photon flux density and light quality induce changes in growth, stomatal development, photosynthesis and transpiration of Withania somnifera (L.) Dunal. plantlets. Plant Cell Tiss Org Cult. 2007;90:141-51. doi.org/10.1007/s11240-006-9191-2.

8. Hogewoning SW, Trouwborst G, Maljaars H, Poorter H, Van leperen W, Harbinson J. Blue light doseresponses of leaf photosynthesis, morphology, and chemical composition of Cucumis sativus grown under different combinations of red and blue light. J Exp Bot. 2010;61:3107-17. doi.org/10.1093/jxb/erq132. 
9. Ohashi-Kaneko K, Matsuda R, Goto E, Fujiwara K, Kurata K. Growth of rice plants under red light with or without supplemental blue light. Soil Sci Plant Nutr. 2006;52:444-52. doi.org/10.1111/j.17470765.2006.00063.x.

10. Kim H-H, Goins GD, Wheeler RM, Sager JC. Green-light supplementation for enhanced lettuce growth under red- and blue-light-emitting diodes. HortSci. 2004;39:1617-22. doi.org/10.21273/hortsci.39.7.1617.

11. Saengtharatip S, Lu N, Takagaki M, Kikuchi M. Productivity and cost performance of lettuce production in plant factory using various light-emitting-diodes of different spectra. ISSAAS Journal. 2018;24:1-9.

12. Snowden MC, Cope KR, Bugbee B. Sensitivity of seven diverse species to blue and green light: interactions with photon flux. PLOS ONE. 2016;11:e0163121. doi.org/10.1371/journal.pone.0163121.

13. Kong S-W, Chung H-Y, Chang M-Y, Fang W. The contribution of different spectral sections to increase fresh weight of boston lettuce. HortSci. 2015;50:1006-10. doi.org/10.21273/hortsci.50.7.1006.

14. Cope KR, Snowden MC, Bugbee B. Photobiological interactions of blue light and photosynthetic photon flux: Effects of monochromatic and broad-spectrum light sources. Photochem Photobiol. 2014;90:574-84. doi.org/10.1111/php.12233.

15. Metallo RM, Kopsell DA, Sams CE, Bumgarner NR. Influence of blue/red vs. white LED light treatments on biomass, shoot morphology, and quality parameters of hydroponically grown kale. Sci Hortic. 2018;235:189-97. doi.org/10.1016/j.scienta.2018.02.061.

16. Han T, Vaganov V, Cao S, Li Q, Ling L, Cheng X, et al. Improving "color rendering" of LED lighting for the growth of lettuce. Sci Rep. 2017;7:45944. doi.org/10.1038/srep45944.

17. Cho J, Park JH, Kim JK, Schubert EF. White light-emitting diodes: history, progress, and future. Laser Photonics Rev. 2017;11:1600147. doi.org/10.1002/Ipor.201600147.

18. Nozue H, Shirai K, Kajikawa K, Gomi M, Nozue M. White LED light with wide wavelength spectrum promotes high-yielding and energy-saving indoor vegetable production. Acta Hortic. 2018;1227:58592. doi.org/10.17660/ActaHortic.2018.1227.74.

19. Lu N, Saengtharatip S, Takagaki M, Maruyama A, Kikuchi M. How do white LEDs' spectra affect the fresh weight of lettuce grown under artificial lighting in a plant factory?-A statistical approach. Agric Sci. 2019;10:957-74. doi.org/10.4236/as.2019.107073.

20. Kusuma P, Pattison PM, Bugbee B. From physics to fixtures to food: current and potential LED efficacy. Hortic Res. 2020;7:56. doi.org/10.1038/s41438-020-0283-7.

21. Yan Z, He D, Niu G, Zhou Q, Qu Y. Growth, nutritional quality, and energy use efficiency of hydroponic lettuce as influenced by daily light integrals exposed to white versus white plus red light-emitting diodes. HortSci. 2019;54:1737-44. doi.org/10.21273/HORTSCI14236-19.

22. Fujiwara K, Eijima K, Yano A. Second-generation LED-artificial sunlight source system available for light effects research in biological and agricultural sciences. In: Proceedings of the 7th Lux Pacifica. Bangkok, Thailand; 2013. p. 140-5. 
23. Ye S, Xiao F, Pan YX, Ma YY, Zhang QY. Phosphors in phosphor-converted white light-emitting diodes: Recent advances in materials, techniques and properties. Mater Sci Eng R Rep. 2010;71:1-34. doi.org/10.1016/j.mser.2010.07.001.

24. Zou J, Zhou C-B, Xu H, Cheng R-F, Yang Q-C, Li T. The effect of artificial solar spectrum on growth of cucumber and lettuce under controlled environment. J Integr Agric. 2020;19:2027-34. doi.org/10.1016/S2095-3119(20)63209-9.

25. Kolling K, George GM, Kunzli R, Flutsch P, Zeeman SC. A whole-plant chamber system for parallel gas exchange measurements of Arabidopsis and other herbaceous species. Plant Methods. 2015;11:48. doi.org/10.1186/s13007-015-0089-z.

26. Fortineau A, Bancal P. An innovative light chamber for measuring photosynthesis by threedimensional plant organs. Plant Methods. 2018;14:21. doi.org/10.1186/s13007-018-0288-5.

27. Jauregui I, Rothwell SA, Taylor SH, Parry MAJ, Carmo-Silva E, Dodd IC. Whole plant chamber to examine sensitivity of cereal gas exchange to changes in evaporative demand. Plant Methods. 2018;14:97. doi.org/10.1186/s13007-018-0357-9.

28. Yano A, Fujiwara K. Plant lighting system with five wavelength-band light-emitting diodes providing photon flux density and mixing ratio control. Plant Methods. 2012;8:46. doi.org/10.1186/1746-48118-46.

29. McCree KJ. The action spectrum, absorptance and quantum yield of photosynthesis in crop plants. Agric Meteorol. 1972;9:191-216. doi.org/10.1016/0002-1571(71)90022-7.

30. Hogewoning SW, Wientjes E, Douwstra P, Trouwborst G, Van leperen W, Croce R, et al. Photosynthetic quantum yield dynamics: from photosystems to leaves. Plant Cell. 2012;24:1921-35. doi.org/10.1105/tpc.112.097972.

31. Inada K. Action spectra for photosynthesis in higher plants. Plant Cell Physiol. 1976;17:355-65. doi.org/10.1093/oxfordjournals.pcp.a075288.

32. Sun J, Nishio JN, Vogelmann TC. Green light drives $\mathrm{CO} 2$ fixation deep within leaves. Plant Cell Physiol. 1998;39:1020-26. doi.org/10.1093/oxfordjournals.pcp.a029298.

33. Terashima I, Fujita T, Inoue T, Chow WS, Oguchi R. Green light drives leaf photosynthesis more efficiently than red light in strong white light: revisiting the enigmatic question of why leaves are green. Plant Cell Physiol. 2009;50:684-97. doi.org/10.1093/pcp/pcp034.

34. Yan Z, He D, Niu G, Zhou Q, Qu Y. Growth, nutritional quality, and energy use efficiency in two lettuce cultivars as influenced by white plus red versus red plus blue LEDs. Int J Agr Biol Eng. 2020;13:3340. doi.org/10.25165/j.ijabe.20201302.5135.

35. Thimijan RW, Heins RD. Photometric, radiometric, and quantum light units of measure: a review of procedures for interconversion. HortSci. 1983;18:818-22.

36. Goins GD, Yorio NC, Sanwo MM, Brown CS. Photomorphogenesis, photosynthesis, and seed yield of wheat plants grown under red light-emitting diodes (LEDs) with and without supplemental blue lighting. J Exp Bot. 1997;48:1407-13. doi.org/10.1093/jxb/48.7.1407. 
37. Liu H, Fu Y, Wang M, Liu H. Green light enhances growth, photosynthetic pigments and CO2 assimilation efficiency of lettuce as revealed by 'knock out'of the 480-560 nm spectral waveband. Photosynthetica. 2017;55:144-52. doi.org/10.1007/s11099-016-0233-7.

38. Lu N, Shimamura S. Protocols, issues and potential improvements of current cultivation systems. In: Kozai T, editor. Smart plant factory. Singapore: Springer; 2018. pp. 31-49. doi.org/10.1007/978-98113-1065-2_3.

39. Rohatgi A. WebPlotDigitizer. https://automeris.io/WebPlotDigitizer. Accessed 8 Jun 2018.

\section{Figures}

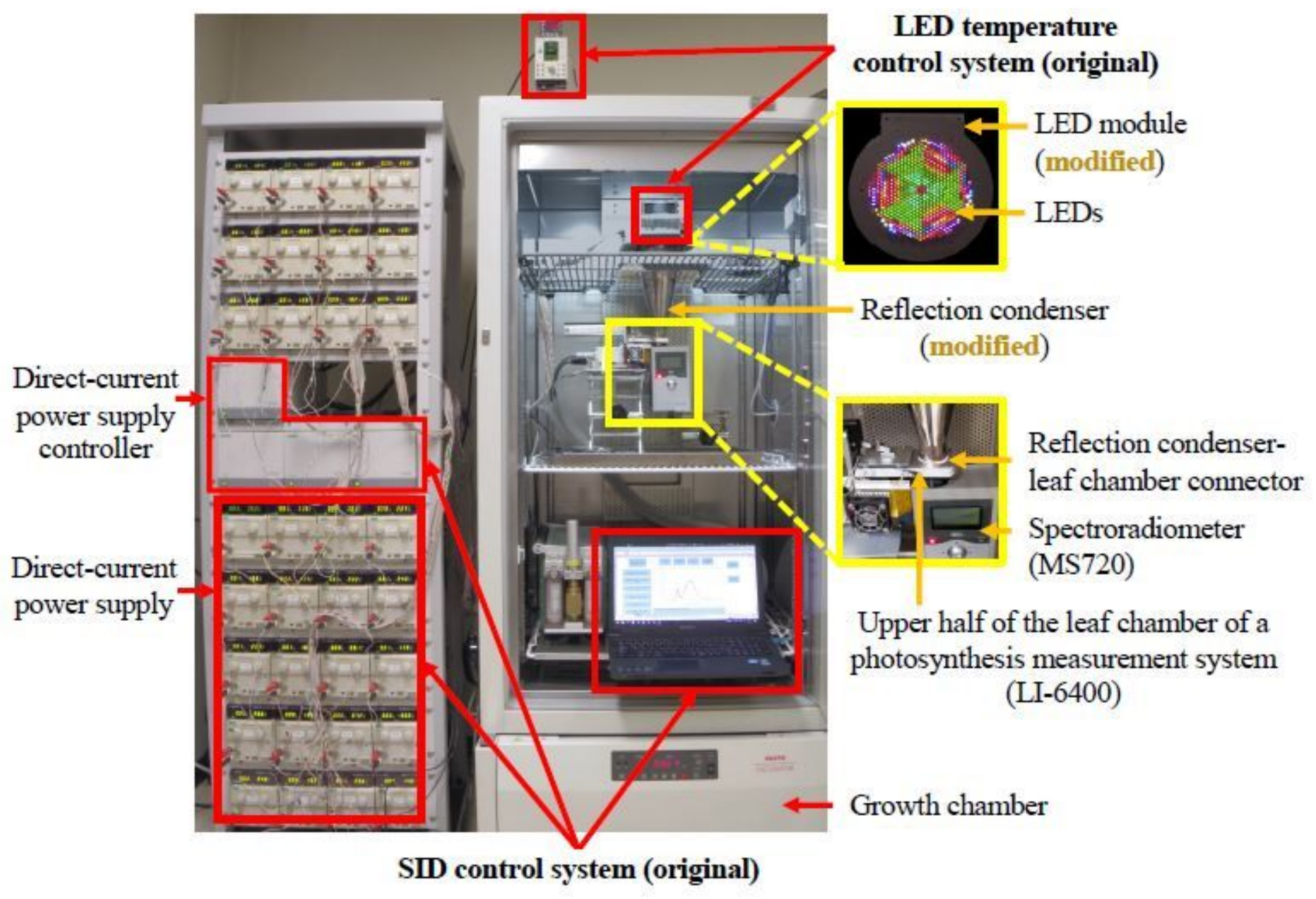

\section{Figure 1}

Hardware configuration of the modified LED-artificial sunlight source system and a spectroradiometer. 


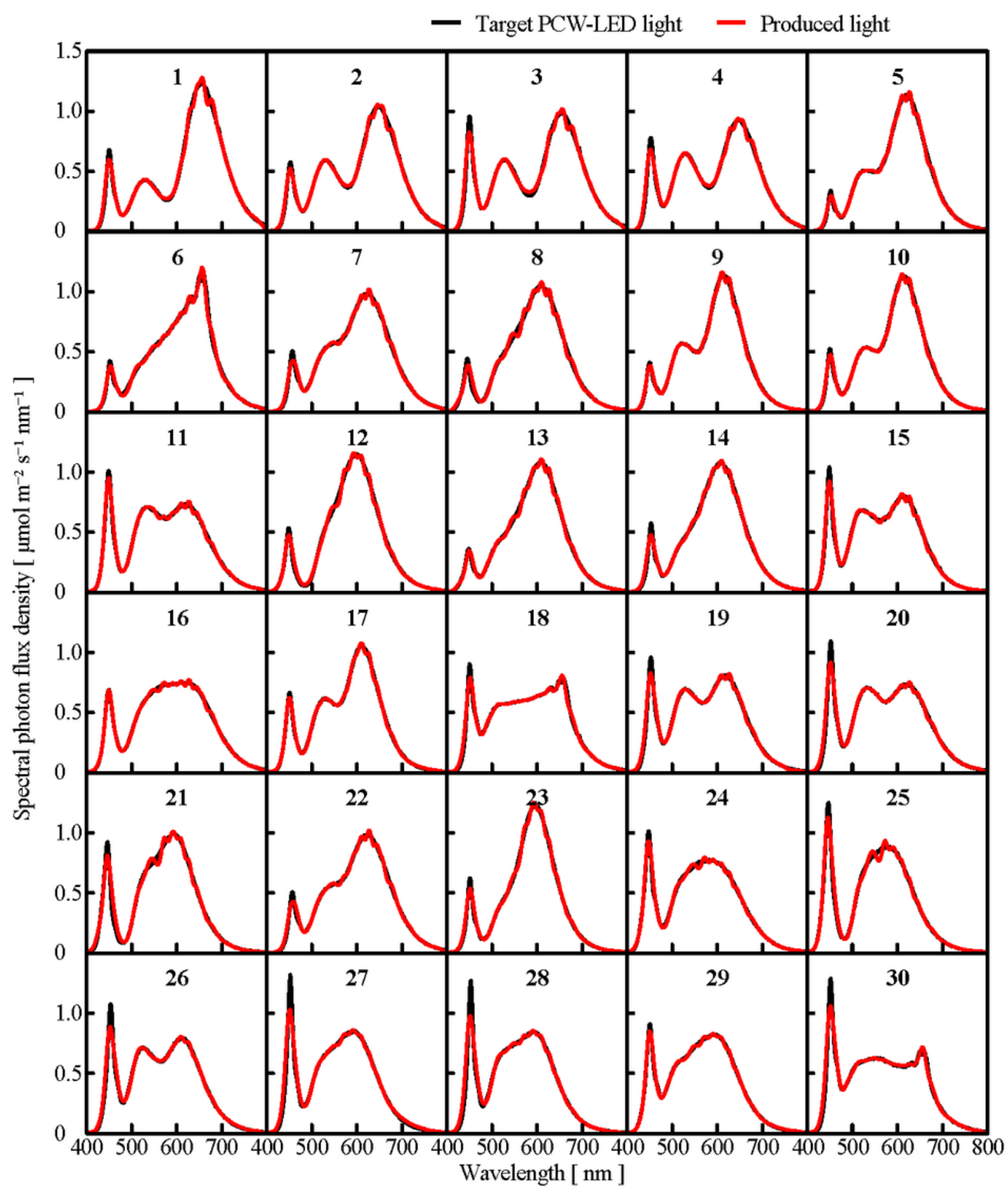

Figure 2

Spectral photon-flux-density distributions (SPDs) for 30 phosphor-converted white LEDs (PCW-LEDs, black lines) at a photosynthetic photon flux density (PPFD) of $150 \mu \mathrm{mol} m-2 \mathrm{~s}-1$. The SPDs (red lines) were measured at a leaf surface level with a spectroradiometer. They were obtained with the modified LED-artificial sunlight source system at a PPFD of $150 \mu \mathrm{mol} m-2 \mathrm{~s}-1$. 

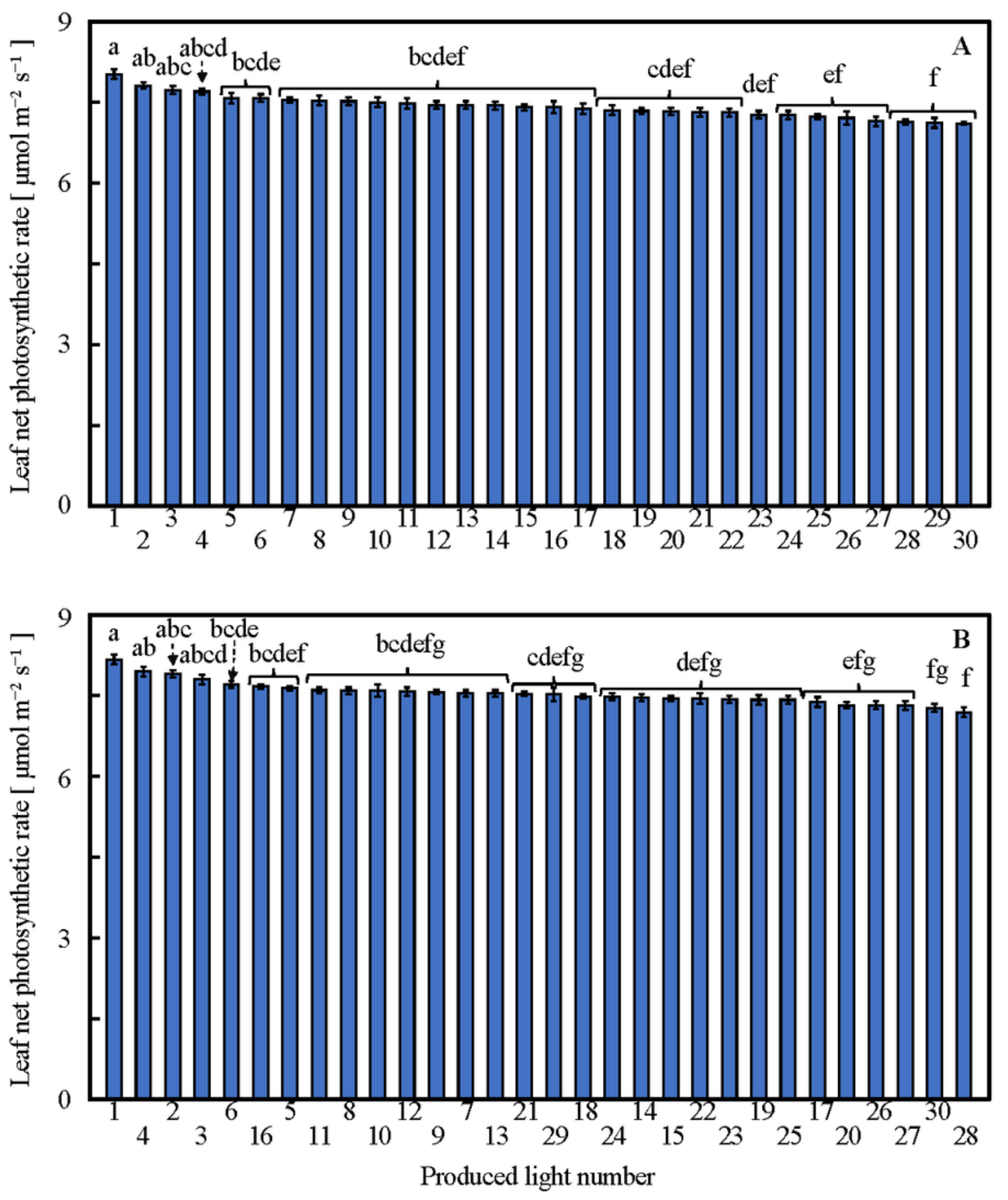

Figure 3

Mean leaf net photosynthetic rate (Pn) of cos lettuce plants with the 30 produced lights at $20(\mathrm{~A})$ and 25 (B) days after sowing. Error bars represent standard errors of the mean Pn. Different letters denote significant differences $(p<0.05)$ by t-test with Holm-Bonferroni $p$-value adjustment $(n=5)$. 

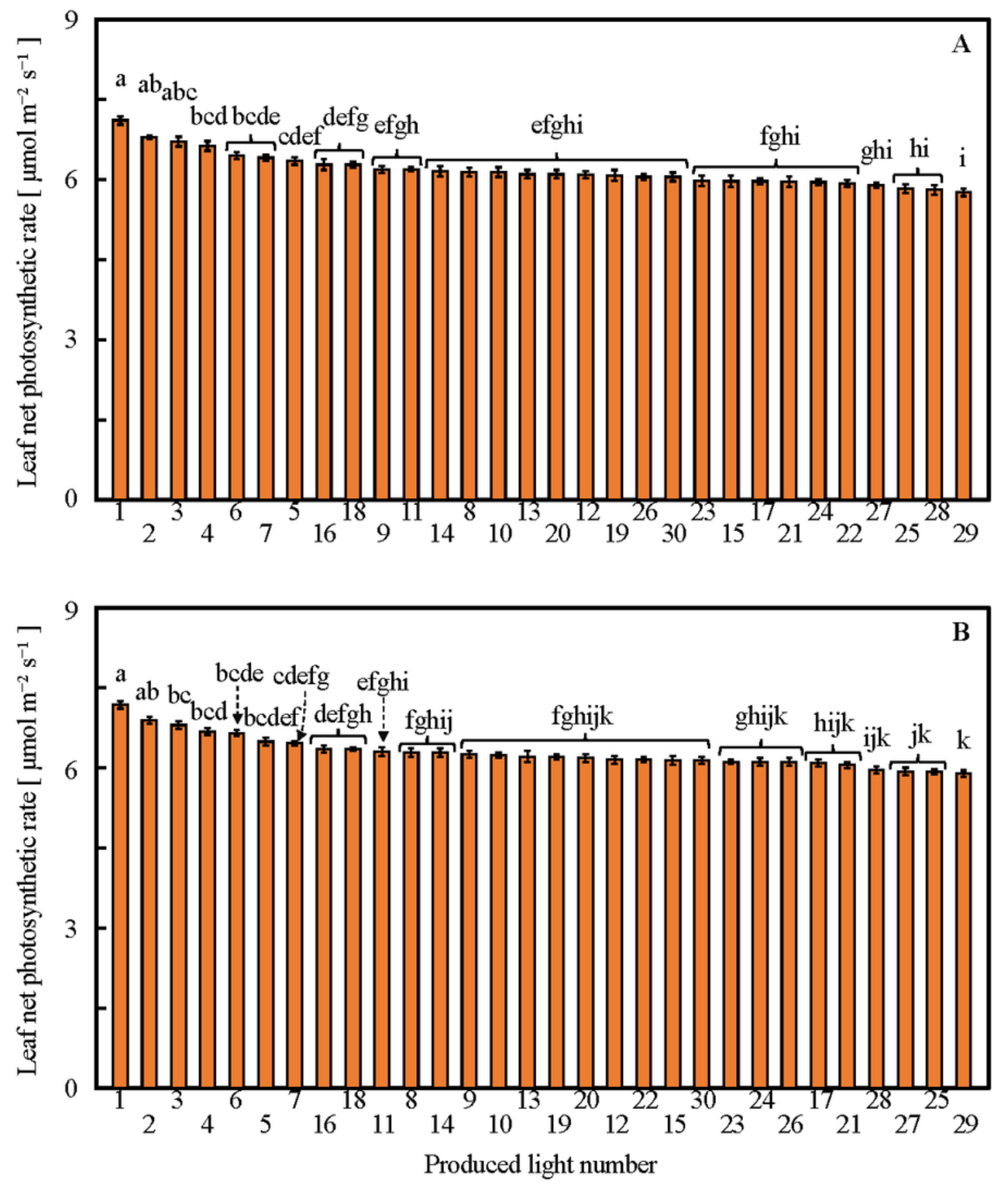

Figure 4

Mean leaf net photosynthetic rates $(\mathrm{Pn})$ of red-leaf lettuce plants with the 30 produced lights at $20(\mathrm{~A})$ and 25 (B) days after sowing. Error bars represent standard errors of the mean Pn. Different letters denote significant differences $(p<0.05)$ by t-test with Holm-Bonferroni $p$-value adjustment $(n=5)$. 

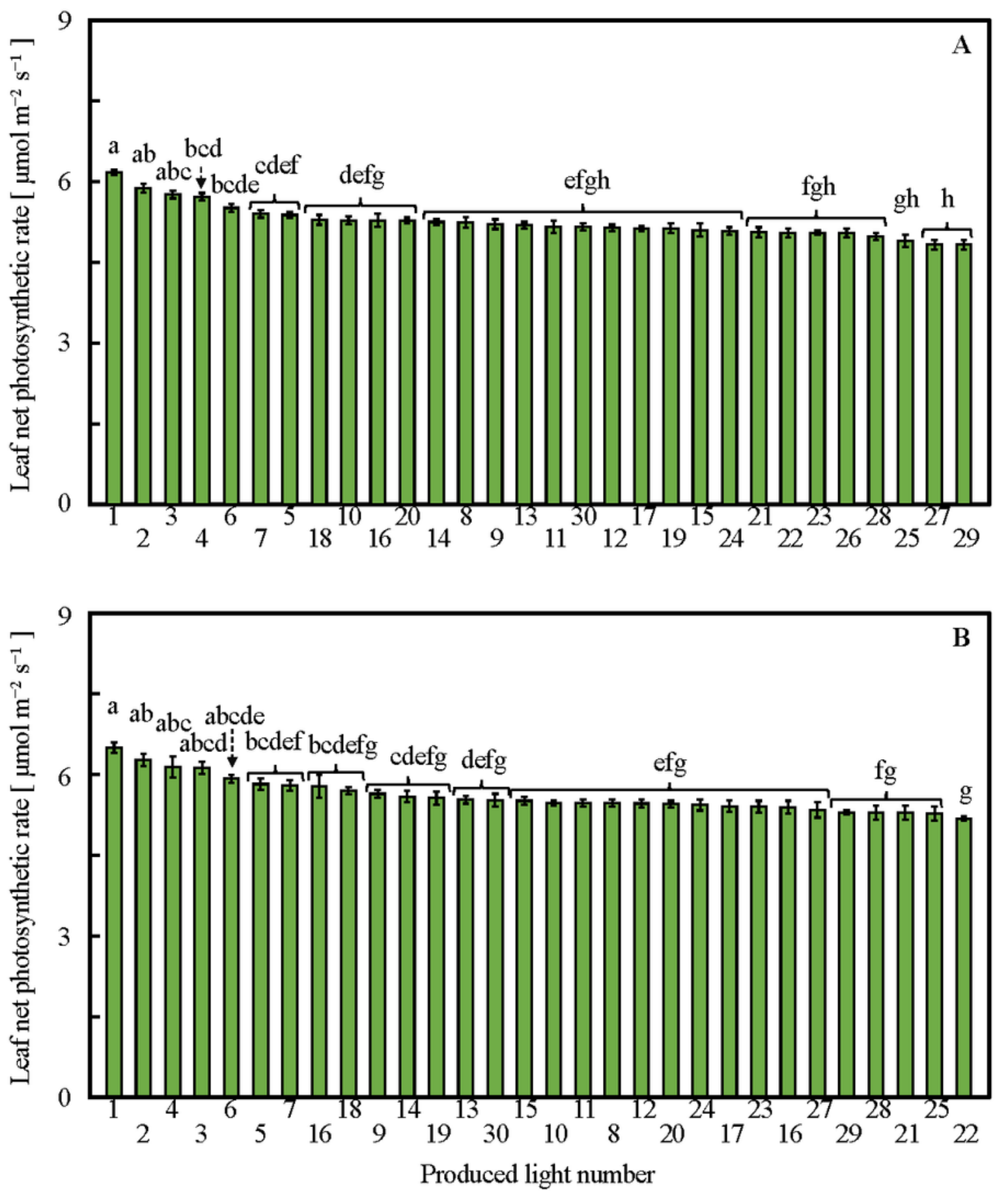

Figure 5

Mean leaf net photosynthetic rates $(\mathrm{Pn})$ of green-leaf lettuce plants with the 30 produced lights at $20(\mathrm{~A})$ and 25 (B) days after sowing. Error bars represent standard errors of the mean Pn. Different letters denote significant differences $(p<0.05)$ by t-test with Holm-Bonferroni $p$-value adjustment $(n=5)$. 


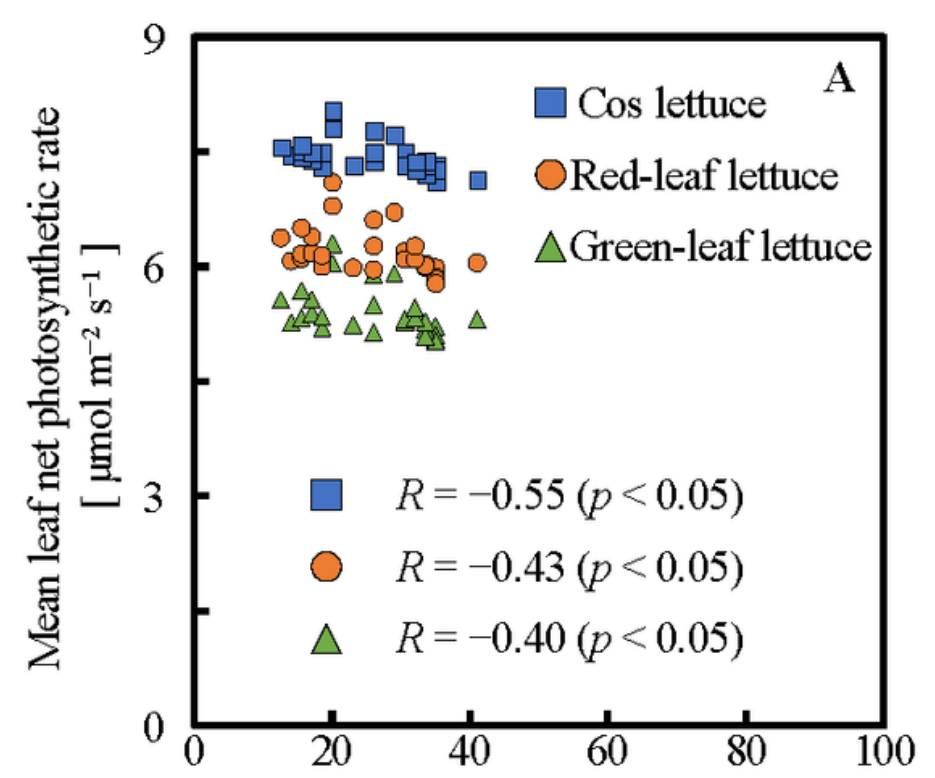

Blue-light photon flux density $(400-500 \mathrm{~nm})$ $\left[\mu \mathrm{mol} \mathrm{m} \mathrm{s}^{-2}\right.$ ]

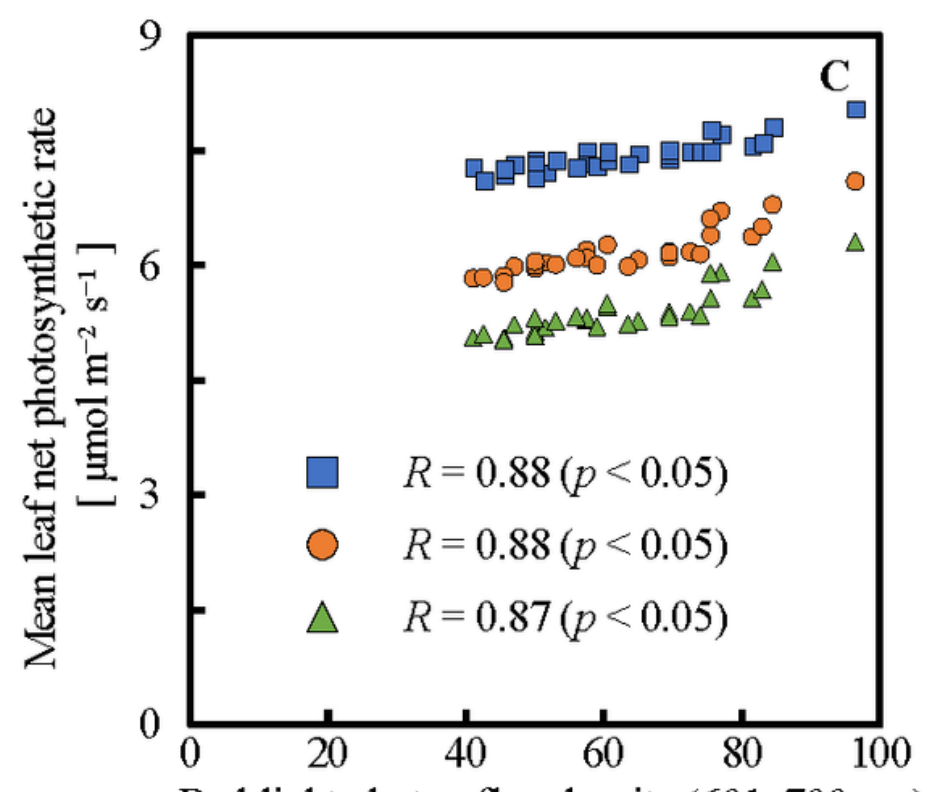

Red-light photon flux density $(601-700 \mathrm{~nm})$ $\left[\mu \mathrm{mol} \mathrm{m} \mathrm{s}^{-2} \mathrm{~s}^{-1}\right.$ ]

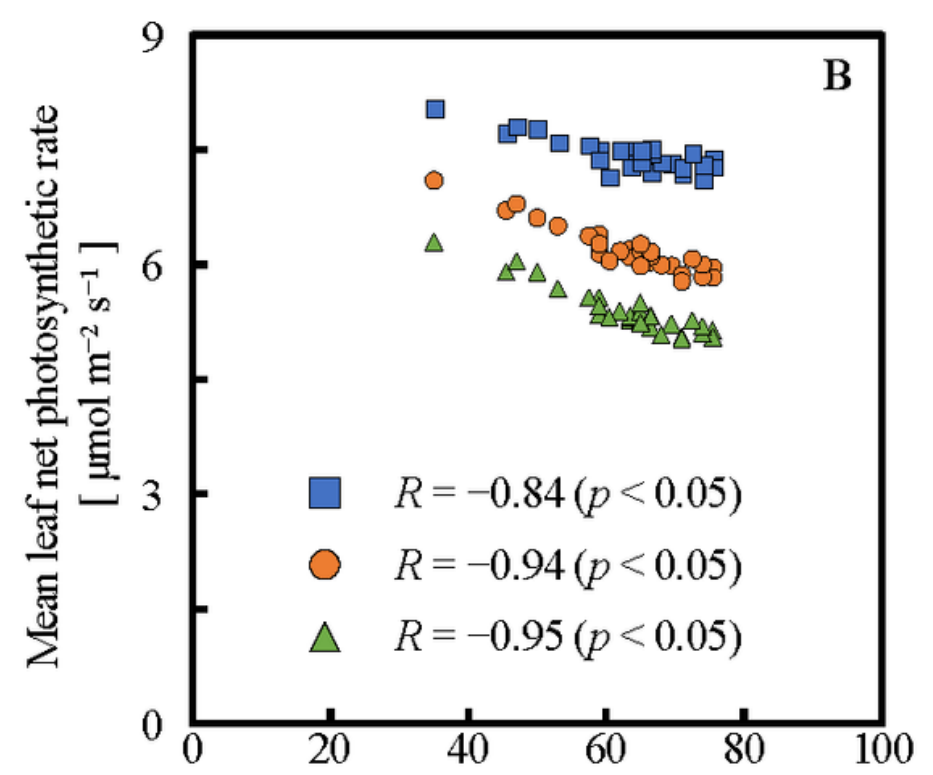

Green-light photon flux density $(501-600 \mathrm{~nm})$

$\left[\mu \mathrm{mol} \mathrm{m} \mathrm{s}^{-2} \mathrm{~s}^{-1}\right]$

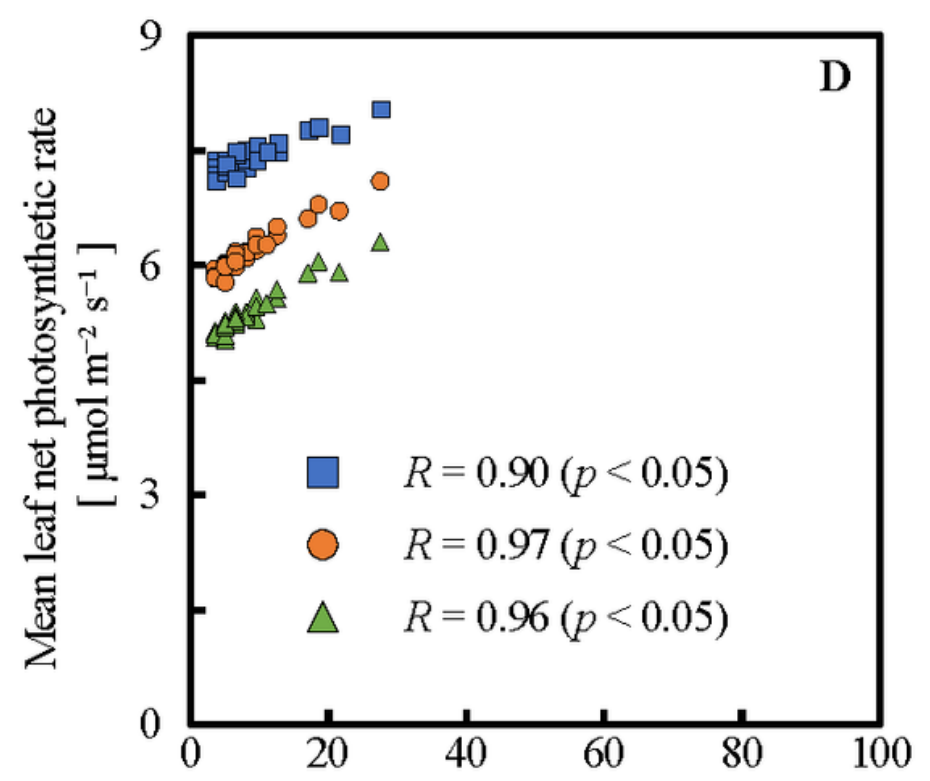

Far-red-light photon flux density $(701-800 \mathrm{~nm})$

$\left[\mu \mathrm{mol} \mathrm{m} \mathrm{s}^{-2} \mathrm{~s}^{-1}\right]$

\section{Figure 6}

Results of correlation analysis between mean leaf net-photosynthetic rates $(\mathrm{Pn})$, which was the mean value of the Pn under the produced lights at 20 days after sowing (DAS) and that at 25 DAS, and bluelight photon flux densities (PFDs; A), green-light PFDs (B), red-light PFDs (C) and far-red-light PFDs (D) from the 30 phosphor-converted white LED lights at a photosynthetic PFD of $150 \mu \mathrm{mol} \mathrm{m}-2 \mathrm{~s}-1$. $R$ is the Pearson correlation coefficient. 

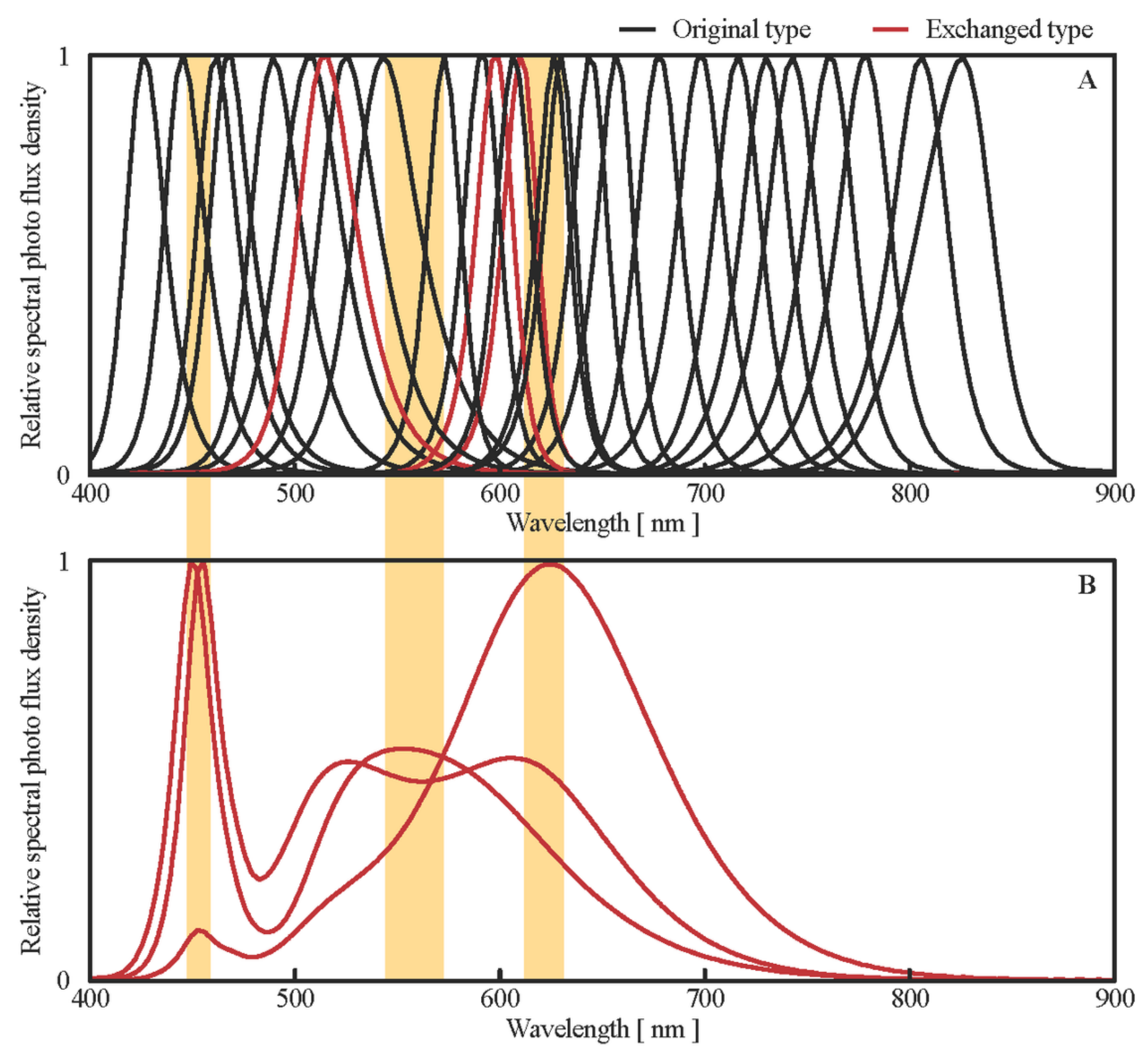

Figure 7

Relative spectral photon-flux-density distributions (SPDs) of the lights from 30 types of LEDs installed on the LED module of the modified LED-artificial sunlight source system: 27 types are monochromatic LEDs (A); the remaining three types are phosphor-converted white LEDs (B). Black lines represent the relative SPDs of LEDs (original type) that were the same as or similar to those of the LEDs installed on the original LED module. Red lines represent the relative SPDs of the LEDs (exchanged type) that differed from those of any LEDs installed on the original LED module (LED model codes are presented in Additional file 5, Table S3). 


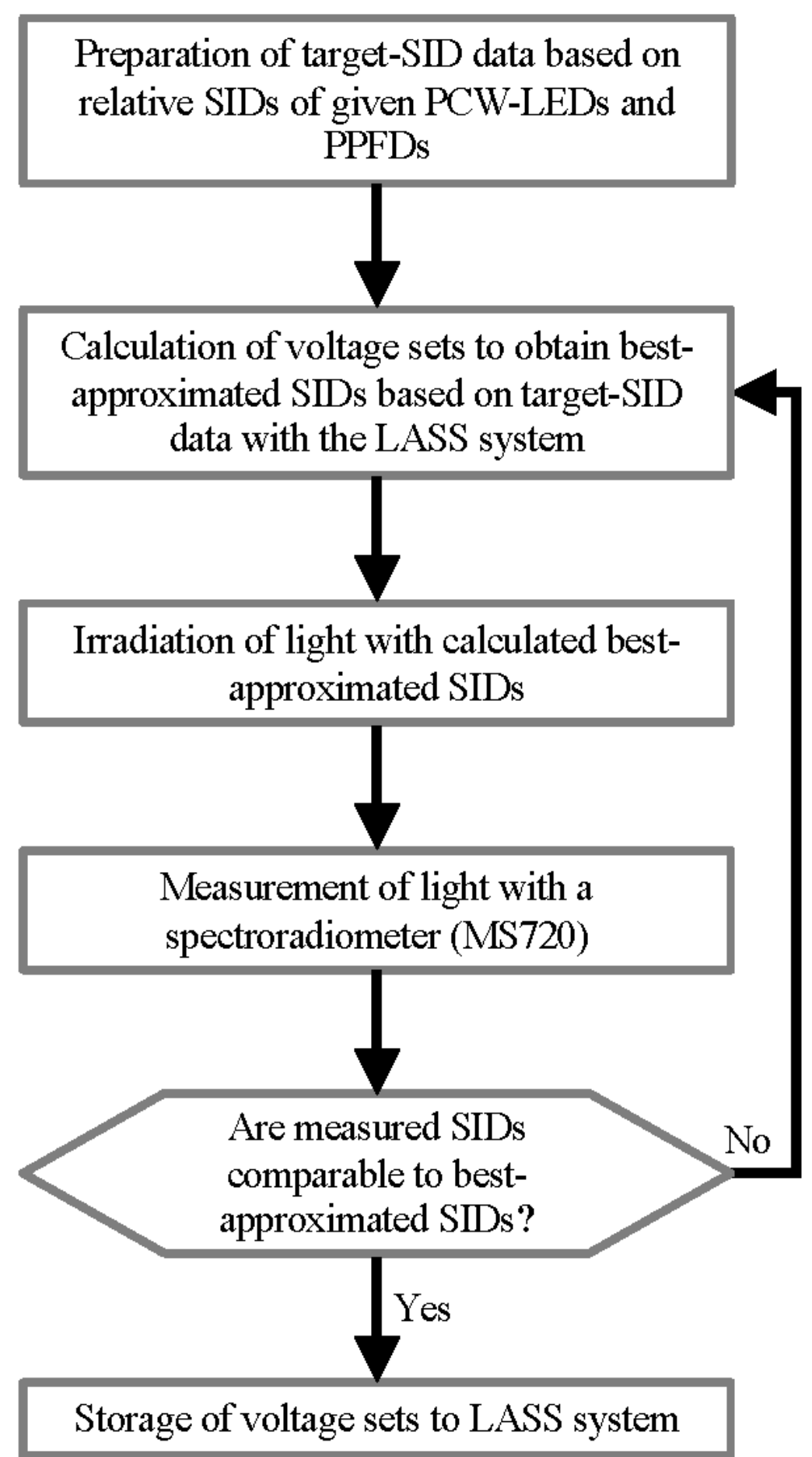

Figure 8

Procedure used for producing phosphor-converted white LED (PCW-LED) lights with the modified LEDartificial sunlight source system. 


\section{Irradiation period and order setting}

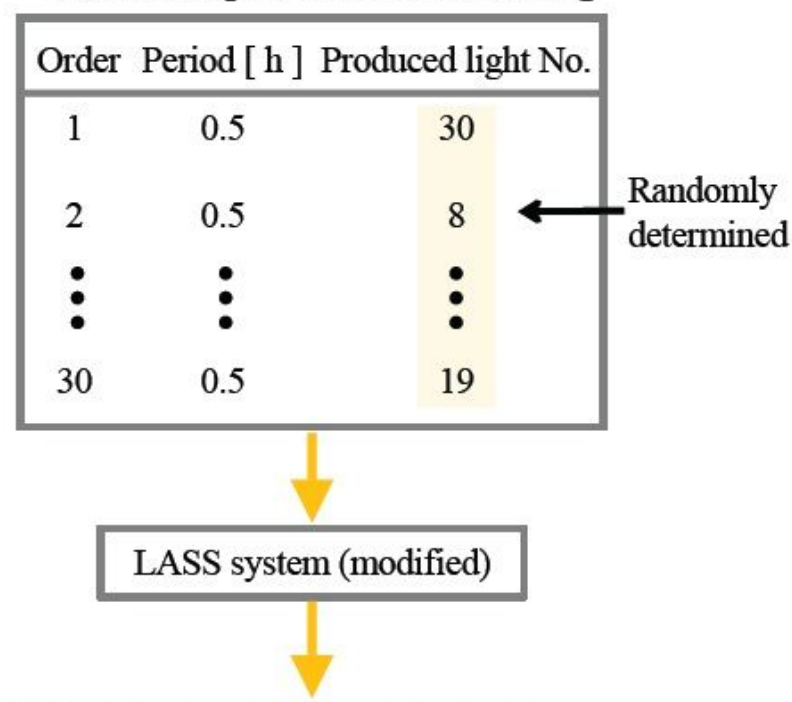

Irradiation pattern in a $\boldsymbol{P}_{\mathrm{n}}$ measurement

(Automatically changing different produced lights)

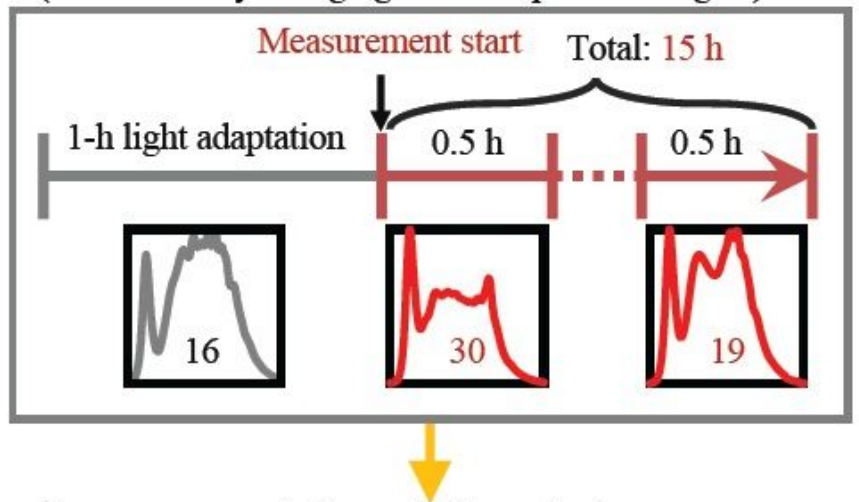

$P_{\mathrm{n}}$ measurement of a cos lettuce plant

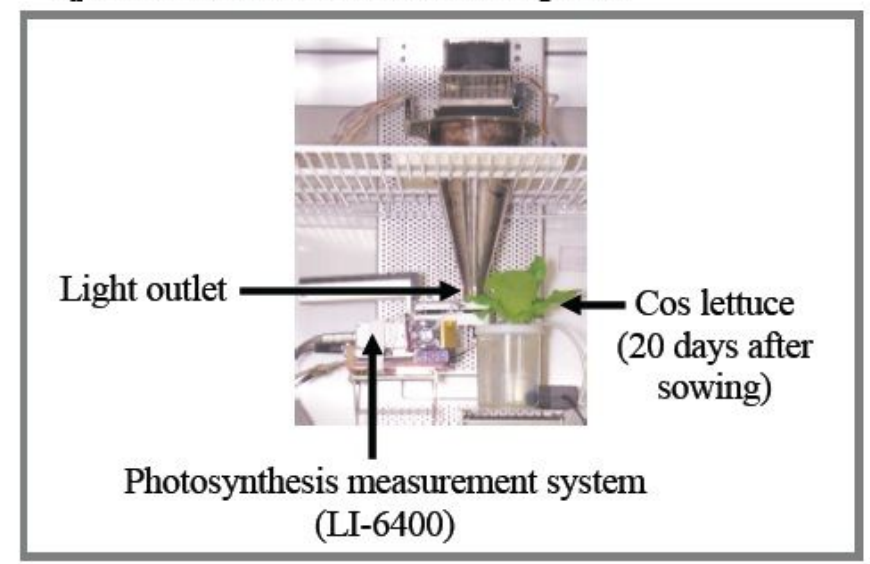

Figure 9

A procedure of the automated leaf net photosynthetic rate $(\mathrm{Pn})$ measurement. The modified LED-artificial sunlight source system (LASS system) automatically supplied the produced light 16 (Figure 2) for $1 \mathrm{~h}$. It then supplied all 30 produced lights successively to an identical leaf in a Pn measurement. 


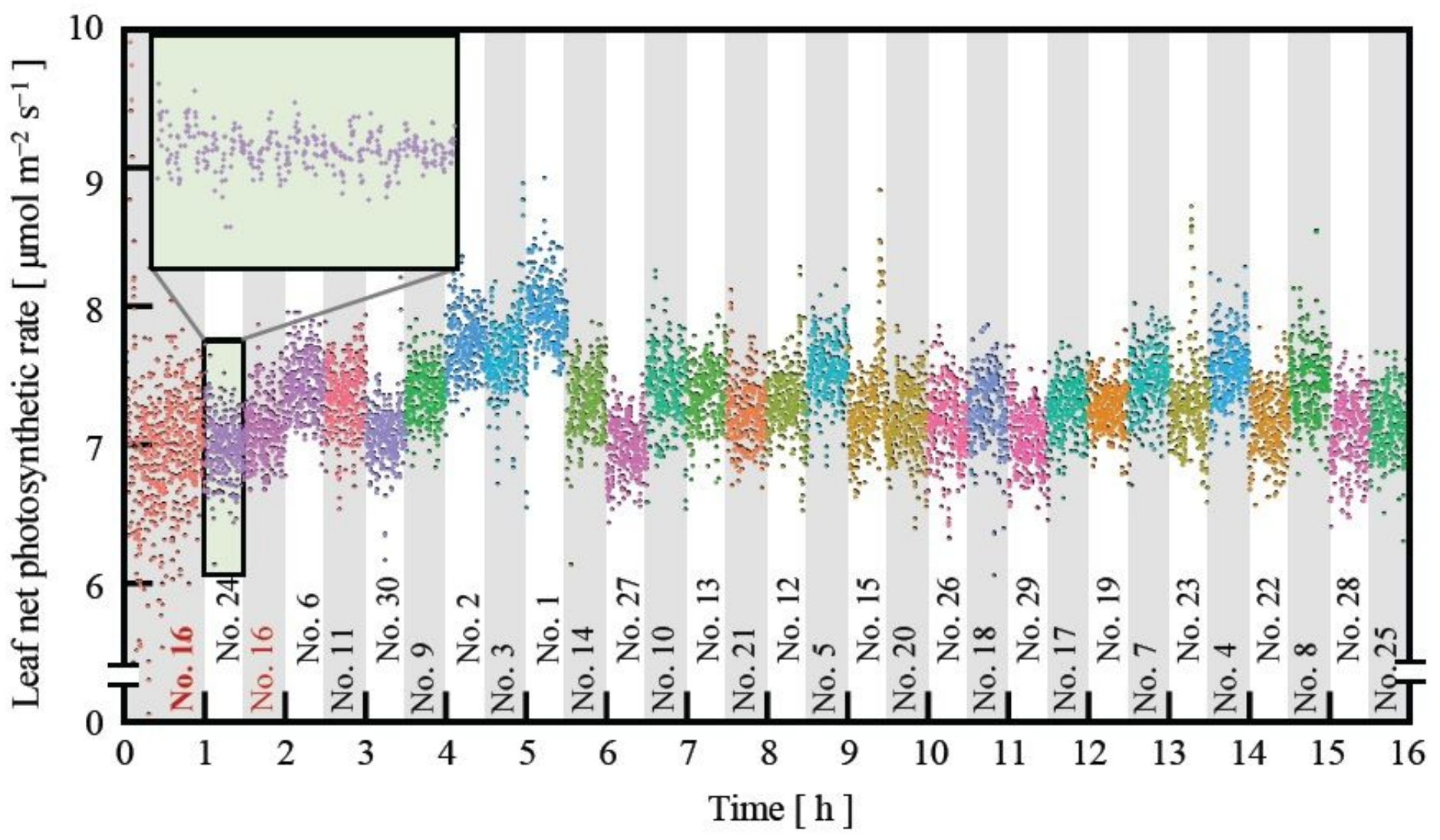

Figure 10

Leaf net photosynthetic rates $(\mathrm{Pn})$ under 30 produced lights in a Pn measurement $(16 \mathrm{~h})$ with a cos lettuce plant at 20 days after sowing. Different serial numbers above the $\mathrm{X}$-axis represent the produced light numbers shown in Figure 2.

\section{Supplementary Files}

This is a list of supplementary files associated with this preprint. Click to download.

- AdditionalFile6TableS4.docx

- AdditionalFile4Figures2.pdf

- AdditionalFile5TableS3.docx

- AdditionalFile3FigureS1.pdf

- AdditionalFile2TabaleS2.docx

- AdditionalFile1TabaleS1.docx 